\title{
MOTIVAÇÕES E BENEFÍCIOS SOCIOECONÔMICOS DO TURISMO RURAL PEDAGÓGICO PARA OS EMPREENDEDORES E A COMUNIDADE RURAL: O CASO DO PROJETO VIVA CIRANDA E ROTEIRO CAMINHOS RURAIS
}

MOTIVATIONS AND SOCIOECONOMIC BENEFITS OF PEDAGOGICAL RURAL TOURISM FOR ENTREPRENEURS AND THE RURAL COMMUNITY: THE VIVA CIRANDA PROJECT AND THE CAMINHOS RURAIS ITINERARY

MOTIVACIONES Y BENEFICIOS SOCIOECONÓMICOS DEL TURISMO RURAL PEDAGÓGICO PARA LOS EMPRENDEDORES Y LA COMUNIDAD RURAL: EL CASO DEL PROYECTO VIVA CIRANDA Y LA GUÍA CAMINOS RURALES

\author{
Marielen Aline Costa da Silva \\ Mestre em Desenvolvimento Rural \\ Universidade Federal do Rio Grande do Sul \\ marielenacs@outlook.com.br
}

\section{Marcelino do Souza}

Professor Doutor do Departamento de Economia e Relações Internacionais e dos Programas de Pós-Graduação em Desenvolvimento Rural e de Agronegócio da Universidade Federal do Rio Grande do Sul marcelino.souza@uol.com.br Data de Submissão: 08/04/2015 Data de Aprovação: 08/06/2015 
Resumo: A dinâmica rural no novo século, baseada na multifuncionalidade da agricultura, assim como a busca da valorização do rural, da reconexão entre cidade e campo e da conscientização de crianças e jovens sobre a produção de alimentos, trouxeram à tona a emergência de novas atividades não agrícolas, como o Turismo Rural Pedagógico (TRP), uma nova modalidade de turismo rural e agroturismo voltada à prática pedagógica. Desta forma, o presente artigo apresenta alguns resultados da dissertação intitulada $A$ prática do turismo rural pedagógico: aspectos motivacionais $e$ impressões dos benefícios para as famílias e comunidades rurais, cujo principal objetivo foi investigar e identificar as motivações e os benefícios socioeconômicos do turismo rural pedagógico para as famílias e a comunidade no entorno do projeto Viva Ciranda e do roteiro Caminhos Rurais. Para tanto, foram realizadas entrevistas semiestruturadas com os empreendedores e a comunidade local. A análise dos dados foi realizada por meio da categorização das respostas, tabulação dos dados e dos softwares Web-QDA e Excel. Os resultados revelaram que o TRP consolida-se como uma interessante opção de investimento e de estratégia de desenvolvimento local, atraindo diferentes perfis de empreendedores. Observou-se que, embora represente uma oportunidade de diversificação econômica, as principais motivações para iniciar e permanecer no TRP, bem como os principais benefícios reconhecidos pelos empreendedores, estão vinculados aos aspectos sociais, como a valorização do meio rural, a satisfação pessoal e a conexão entre rural e urbano. Além disso, a pesquisa verificou o reconhecimento e a valorização dessa prática pela comunidade do entorno das propriedades pedagógicas.

Palavras-chave: Turismo rural pedagógico. Turismo rural. Motivações. Desenvolvimento rural.

Abstract: The rural dynamics in the new century, based on the multifunctionality of agriculture and the pursuit of rural appreciation, the (re)connection between city and country, and raising children and young people's awareness about food production, has led to the emergence of non-agricultural activities such as the Pedagogical Rural Tourism (PRT), a new modality of rural tourism focused on educational practices. This study presents some results of the dissertation entitled "A prática do turismo rural pedagógico: aspectos motivacionais e impressões dos benefícios para as famílias e comunidades rurais" (The practice of educational rural tourism: motivational aspects and impressions of the benefits for families and rural communities), which aimed to investigate and identify the motivations and socioeconomic benefits of Pedagogical Rural Tourism for families and the local community around the Viva Ciranda project and the Roteiro Caminhos Rurais (Rural Routes Itinerary). For this purpose, semi-structured and open interviews with entrepreneurs and the local community were designed, and closed questions using the Likert scale were applied. Qualitative data analysis was performed through categorization of responses and the WEB-QDA software. Quantitative data were organized and tabulated in Excel software. The results revealed that PRT is consolidated as an interesting option for investment and a strategy for local development, attracting different profiles of entrepreneurs and institutions. Despite representing an opportunity for economic diversification, the main inducement to start, and to remain in the PRT, as well as its main benefits, are related to social issues such as appreciation of rural environment, personal satisfaction and the connection between rural and urban. The appreciation of this practice by the community around the pedagogical properties was also observed.

Keywords: Pedagogical rural tourism. Rural development. Motivations.

Resumen: La dinámica rural en el nuevo siglo, basada en la multifuncionalidad de la agricultura, así como la búsqueda de la valorización de lo rural, de la reconexión entre ciudad y campo y de la concienciación de niños y jóvenes sobre la producción de alimentos, trajeron a la luz el surgimiento de nuevas actividades no agrícolas, como el Turismo Rural Pedagógico (TRP), una nueva modalidad de turismo rural y agroturismo dirigida a la práctica pedagógica. De esta forma, el presente artículo 
presenta algunos resultados de la disertación intitulada La práctica del turismo rural pedagógico: aspectos motivacionales e impresiones de los beneficios para las familias y comunidades rurales, cuyo principal objetivo fue investigar e identificar las motivaciones y los beneficios socioeconómicos del turismo rural pedagógico para las familias y la comunidad en el entorno del proyecto Viva Ciranda y de la guía Caminos Rurales. Para ello fueron realizadas entrevistas semiestructuradas con los emprendedores y la comunidad local. El análisis de los datos fue realizado por medio de la categorización de las respuestas, tabulación de los datos y de los softwares Web-QDA y Excel. Los resultados revelaron que el TRP se consolida como una interesante alternativa de inversión y de estrategia de desarrollo local, atrayendo diferentes perfiles de emprendedores. Se observó que, aunque represente una oportunidad de diversificación económica, las principales motivaciones para iniciar y permanecer en el TRP, así como los principales beneficios reconocidos por los emprendedores, están vinculados a los aspectos sociales, como la valorización del medio rural, la satisfacción personal y la conexión entre rural y urbano. Asimismo, la investigación verificó el reconocimiento y la valorización de esa práctica por parte de la comunidad del entorno de las propiedades pedagógicas.

Palabras clave: Turismo rural pedagógico. Turismo rural. Motivaciones. Desarrollo rural.

INTRODUÇÃO

vista do reconhecimento dos aspectos socioculturais e ambientais da
agricultura, bem como da nova dimensão dada ao desenvolvimento
a partir da década de 1990, novos conceitos surgiram, entre eles o da multifuncionalidade da agricultura, ligado à valorização das diversas funções que a mesma exerce. Neste sentido, os debates acerca da multifuncionalidade da agricultura passaram a ser marcados pela legitimação e pelo interesse das diversas esferas sociais sobre as funções econômica, social, ambiental, cultural e desegurança alimentarque a agricultura apresenta. A partir dessa nova percepção da agricultura, para além das suas funções produtivas, novas ocupações não agrícolas passaram a despontar no meio rural. Entre estas ocupações e serviços destaca-se o turismo rural (TR) e o agroturismo como atividades capazes de dinamizar o espaço rural promovendo o seu desenvolvimento.

Para autores como Campanhola e Graziano da Silva (2000) e Tulik (2003), o turismo rural tem como principal característica a utilização das especificidades do meio rural, como paisagem e patrimônio cultural, além das atividades agropecuárias, na promoção do lazer e do turismo. Desse modo, a crescente busca pela integração entre cidade e campo por meio de atividades como o agroturismo e o turismo rural, da mesma forma que o reconhecimento da necessidade de valorização do modo de vida rural e a importância 
da conscientização de crianças e jovens sobre as atividades de produção agropecuária, em especial a produção de alimentos, despertaram a emergência de uma nova modalidade de turismo rural e agroturismo voltada à prática pedagógica, o Turismo Rural Pedagógico (TRP).

O TRP é definido como "[...] um conjunto de atividades práticas realizadas no âmbito da propriedade rural, que utiliza como recurso didático as atividades agrícolas, a produção agropecuária e os recursos naturais e culturais ali existentes" (KLEIN, 2012:42). Segundo a autora, o mesmo caracteriza-se como uma ferramenta capaz de vincular diretamente as funções educativa e ambiental, além de influenciar de maneira indireta sobre as funções socioeconômicas e de segurança alimentar. Além de um processo educacional, o TRP mostra-se como uma estratégia de revalorização do rural, resgate dos valores culturais das comunidades, assim como de bens e serviços, por meio da troca de experiências entre citadinos e produtores rurais.

Segundo autores como Ohe (2007), Hinrichs (2008) e Adams (2008), as propriedades rurais pedagógicas possuem grande importância no processo de educação alimentar e combate a doenças de crianças e jovens relacionadas ao mau hábito alimentar. Além disso, O TRP proporciona benefícios aos consumidores que podem conhecer o processo de produção de alimentos e aos agricultores, que têm sua cultura valorizada e preservada por meio dessa prática. Neste sentido, diversas experiências internacionais em países, como Itália, Estados Unidos, Japão, França, Noruega, vêm demonstrando a essencialidade desse tipo de atividade para as questões socioeconômicas e de segurança alimentar. No Brasil, ainda são pouco numerosos os estudos, além de estarem vinculados muito mais às funções educativas do que às questões socioeconômicas levantadas por esse tipo de atividade.

Assim, esta pesquisa se propôs a contribuir para a compreensão analítica sobre a prática do turismo rural pedagógico no Brasil, bem como colaborar para promoção desta prática de turismo rural e para elaboração e implementação de políticas públicas, concentrando-se na problemática das motivações dos empreendedores do turismo rural pedagógico e dos principais benefícios que esta prática promove às famílias e à comunidade na qual estão inseridos. Assim, 
o presente estudo tem como principal objetivo analisar as motivações e os benefícios socioeconômicos do turismo rural pedagógico para as famílias e a comunidade do seu entorno.

\section{O TURISMO RURAL PEDAGÓGICO NA DINÂMICA DO NOVO SÉCULO}

Separar as transformações de cunho tecnológico que atingiram a agricultura nas últimas décadas das alterações sociais, políticas e culturais ocorridas no meio rural e urbano é uma tarefa difícil, uma vez que estas caminham lado a lado. Estas mudanças, em especial as advindas a partir da década de 1990, exerceram forte influência na emergência de uma nova dinâmica rural.

A implementação do uso de novas tecnologias na agricultura não foi responsável apenas pela modernização e pelo aumento da produção no campo, mas também trouxe consequências negativas ao meio rural. Segundo Kageyama (2008), a especialização da agricultura provocou uma redução na demanda de força de trabalho, implicando a redução da população rural e a especialização dos mercados locais. Estes aspectos atribuíram à visão tradicional da ruralidade três características essenciais: baixa densidade populacional, ocupação exclusivamente agrícola e situação de atraso material e cultural. Logo, de acordo com esta visão, o rural representa uma dicotomia ao urbano, o que teve como consequência um grande número de migrações para as cidades.

Para Wanderley (2000), a crise do modelo produtivista de modernização agrícola e as demais transformações socioculturais decorrentes desse processo influenciaram de maneira marcante o modo de vida das comunidades rurais e a relação entre rural e urbano, tornando-se responsáveis pelo surgimento de um "novo" conceito de ruralidade. De acordo com Graziano da Silva (2002), a partir das mudanças ocorridas nas diversas esferas do rural, este não pode mais ser pensado apenas como um lugar que produz mercadorias agrícolas e oferece mão de obra. As mudanças permitiram uma nova e maior reflexão sobre o rural e dessa forma a concretização de uma nova concepção sobre o significado do meio rural. 
Assim, frente a esta nova conjuntura de transformações, novas dinâmicas de ocupação, revalorização do rural e da agricultura familiar, entre outras, emergem novas abordagens, entre elas a multifuncionalidade, que se apresenta como alicerce às diversas funções desempenhadas pela agricultura. O debate da multifuncionalidade, fruto da crise do modelo produtivista, tem introduzido uma nova concepção de desenvolvimento, não do ponto de vista histórico da percepção setorial e empresarial, mas de uma abordagem integrada e territorial (CARNEIRO, 2006).

Segundo Cazzella et al. (2009), as novas dimensões dadas às dinâmicas rurais por meio da abordagem multifuncional vão ao encontro do processo social de desenvolvimento rural sustentável que tem suas bases na equidade social e preservação ambiental. Dessa forma, o uso desta categoria como ferramenta político-institucional para a formulação de políticas públicas de desenvolvimento rural promove a reconexão entre o Estado e os atores sociais rurais, bem como a ressignificação do rural pelos diversos setores da sociedade. Assim, a complexidade do rural exige que tais políticas sejam pensadas a partir do território e não mais apenas setorialmente, garantindo a emergência de novas possibilidades de emprego; renda, e a superação de desequilíbrios, como a pobreza e o êxodo rural.

Neste contexto das novas oportunidades de produção de bens e serviços no meio rural, Graziano da Silva (1997) destaca a importância do conjunto de atividades não agrícolas que cada vez mais respondem pela dinâmica populacional. Entre as novas funções e ocupações, o autor ressalta os serviços de lazer, moradia e de preservação e conservação ambiental, como o turismo rural. Segundo Campanhola e Graziano da Silva (2000), o turismo rural está relacionado a qualquer atividade de lazer e turismo que seja realizada em áreas rurais, envolvendo, além do agroturismo, outras atividades não relacionadas a propriedades agropecuárias produtivas ou com produção agropecuária. Neste sentido, o turismo rural, em especial o agroturismo, vem ganhando destaque pela sua capacidade de aproximar visitantes e agricultores por meio da interação com as práticas agropecuárias desenvolvidas nas propriedades rurais.

Dessa forma, frente a tal conjuntura emergem modalidades contemporâneas de turismo que abarcam características do turismo rural e do agroturismo, como 
o turismo rural pedagógico (TRP). Este se caracteriza pelo uso de atrativos, como a exploração das atividades agropecuárias presentes nas propriedades rurais, o uso do patrimônio sociocultural do meio rural, uso dos "saber-fazeres" do homem do campo, entre outros atrativos comuns ao agroturismo e ao turismo rural, como ferramenta para a prática pedagógica. Neste sentido, o turismo rural pedagógico não pode ser classificado apenas como uma modalidade dentro do agroturismo ou do turismo rural, mas sim como uma nova categoria que possui elos com estes segmentos.

Assim, o turismo rural pedagógico pode ser compreendido como uma atividade "nova", que tem como base o uso dos recursos disponíveis no meio rural como ferramenta didática, o que vai ao encontro, muitas vezes, dos objetivos e das características do turismo pedagógico e/ou turismo educativo. No Brasil, o termo TRP surgiu no ano de 2005 e foi definido pela Associação Brasileira de Turismo Rural (ABRATURR/ECA JR., 2005, p.6) como sendo:

[...] o conjunto de atividades turísticas desenvolvidas no meio rural, comprometido com o meio ambiente e a produção agropecuária e/ou com os valores históricos de produção no universo rural, agregando valor a produtos e serviços, resgatando e promovendo o patrimônio cultural natural da comunidade que fundamentalmente tem um acompanhamento didático pedagógico com o objetivo de aquisição de conhecimento.

Alguns países europeus, bem como Japão, Estados Unidos e Noruega, apesar de não utilizarem o termo turismo rural pedagógico, já vêm desenvolvendo nas propriedades rurais atividades pedagógicas ao longo das últimas décadas. Segundo Adams (2008), quando bem planejadas as propriedades rurais educacionais podem resultar em um cenário mais saudável, com a satisfação de saber que, por meio desta se está contribuindo para a preservação das habilidades tradicionais e/ou da arte do conhecimento do meio rural para o mundo. Admitindo esta ideia, Klein, Troian e Souza (2011, p.119), alegam que o TRP "possibilita o contato com diferentes culturas e costumes, aproximando pessoas, integrando campo e cidade e valorizando espaços antes configurados como lugares atrasados e sem perspectivas de desenvolvimento".

Além do crescimento econômico, McEnroe (2010) sugere que esta modalidade de turismo é responsável pelo aumento da liberdade e da segurança 
dos agricultores. Para o autor, esta multifuncionalidade das atividades agrícolas, como atividades pedagógicas e de produção, é fundamental para os agricultores que valorizam a liberdade. A renda adicional oriunda do turismo pedagógico garante que o produtor trabalhe de acordo com a sua própria vontade, no que se refere a sua necessidade de produzir alimentos e matérias-primas para as grandes indústrias agroalimentares, tornando seu trabalho dependente dessas.

Dessa forma, o turismo rural pedagógico mostra-se como um possível agente promissor de desenvolvimento local, na medida em que busca esse desenvolvimento a partir do uso e da valorização dos recursos locais, bem como por meio da participação direta dos atores locais no processo de planejamento, implementação e controle das ações de desenvolvimento. Assim, identificar e classificar as razões pelas quais os empreendedores do TRP investiram nessa modalidade de turismo, bem como suas motivações para permanecer no mesmo, tornam-se uma ferramenta fundamental na compreensão e na promoção do desenvolvimento das comunidades envolvidas.

\section{METODOLOGIA}

O presente estudo tem como base os resultados da dissertação intitulada A prática do turismo rural pedagógico: aspectos motivacionais e impressões dos benefícios para as famílias e comunidades rurais. A pesquisa teve como objetos de estudo os proprietários de empreendimentos de turismo rural pedagógico e membros da comunidade de entorno pertencentes a dois roteiros turísticos: Caminhos Rurais e o projeto Viva Ciranda. O segmento do turismo rural pedagógico foi escolhido por representar uma interessante estratégia socioeconômica aos proprietários rurais e ferramenta educacional aos estudantes. Quanto aos roteiros, estes foram escolhidos por tratarem de duas experiências consolidadas de turismo rural pedagógico no sul do Brasil, já que o país conta com um número limitado de iniciativas nesta área, bem como por apresentarem uma série de características distintas, por exemplo, no que se refere ao apoio público e à organização dos proprietários rurais.

O método utilizado nesta pesquisa está alicerçado nas abordagens qualitativa e quantitativa, ou seja, método misto, de caráter descritivo, a partir de uma 
aproximação ao que se denomina estudo múltiplo de caso. Optou-se por tal método, pois a problemática de pesquisa e objetivos definidos exigiram a coleta e a interpretação de dados qualitativos, assim como a exploração e o tratamento de dados numéricos. Quanto ao tipo de amostragem escolhida, optou-se pela amostragem intencional não probabilística.

Quanto à coleta de dados, utilizaram-se entrevistas semiestruturadas com questões abertas e fechadas, bem como a pesquisa bibliográfica. Dessa forma, buscando responder aos objetivos propostos, as entrevistas semiestruturadas foram aplicadas a dois grupos de 4 e 10 empreendedores de turismo pedagógico rural: 10 participantes do projeto Viva Ciranda e 4 do Roteiro Caminhos Rurais. Durante a primeira semana do mês de julho de 2014 foram entrevistados os proprietários das seguintes propriedades do roteiro Caminhos Rurais: Sítio do Tio Juca, Sítio dos Herdeiros, Sítio do Mato e Granja Santantônio. Já entre os dias 14 a 19 de julho do mesmo ano, foi realizada a coleta dos dados das propriedades do Projeto Viva Ciranda: Apiário PFAU, Propriedade Ango Kersten, Família Schroeder, Recanto das Arrozeiras, Sítio Vó Bia, Agrícola da Ilha, CTG Chaparral, Rancho Alegre, Família Roos e Anturioville Holz. No mesmo período também foi aplicada a mesma modalidade de entrevista a 8 moradores das comunidades residentes no entorno das propriedades rurais pesquisadas.

Já quanto às questões fechadas, estas foram aplicadas como o objetivo de identificar e classificar as motivações dos proprietários rurais para entrarem e permanecerem na atividade de turismo rural pedagógico. Para tal, foi utilizada a escala de Likert, na qual foram listadas nove razões para a tomada de decisão de empreender no TRP e seis razões para permanecer neste segmento. Assim, estas razões foram classificadas de 1 a 5 pelos proprietários rurais de acordo seu nível de importância, ou seja, nível 1 considerado como "não relevante", nível 2 considerado "pouco relevante", nível 3 considerado "neutro", nível 4 considerado "relevante" e nível 5 considerado "muito relevante".

Em relação à análise dos dados, primeiramente os dados qualitativos foram transcritos e, posteriormente, foram ordenados e classificados de acordo com o grupo pesquisado. Ou seja, as entrevistas foram desmembradas em categorias temáticas, utilizando-se critérios preestabelecidos. Para a organização e 
gerenciamento destes dados, foi utilizado o software Web-QDA desenvolvido para a análise de dados qualitativos.

No que se refere ao perfil dos proprietários rurais e dos empreendimentos, estes foram classificados em três categorias de acordo com o tipo de atividade econômica realizada em cada estabelecimento rural. Dessa forma, as categorias estabelecidas foram as seguintes: Grupo 1 (AF+TR) - desenvolvem em suas propriedades atividades deturismo rural exploração agrícola com características da agricultura familiar. Grupo 2 (TR) - apresentam como atividade econômica apenas o turismo rural, a exploração agrícola está vinculada exclusivamente à subsistência e à demonstração nas práticas de turismo. Grupo $3(\mathrm{AE}+\mathrm{TR})$ - tem com base econômica da propriedade a agropecuária e a agricultura, sendo estas de caráter empresarial, enquanto as atividades de turismo rural apresentam-se na propriedade com baixo e/ou nenhum valor econômico.

Ainda no que diz respeito ao tratamento dos dados qualitativos, buscando uma melhor compreensão dos diferentes tipos de benefícios gerados pelo TRP aos empreendedores, suas famílias e comunidade local, estes foram categorizados em 4 grandes grupos baseados nos fatores da racionalidade e da racionalização descritos por Weber, ou seja, fatores que orientam a ação social. São eles: Benefícios Econômicos, que levam em consideração apenas os aspectos financeiros proporcionados pelo TRP; Benefícios Sociais, que se referem exclusivamente aos fatores sociais; Benefícios "Formal-Substantivos", que possuem ênfase nos benefícios econômicos, mas consideram em segundo plano os benefícios sociais; Benefícios "Substantivo-Formal", que consideram em primeiro lugar os aspectos sociais, sem desconsiderar os fatores econômicos promovidos pelo TRP.

Já em relação aos dados quantitativos, para sua análise calculou-se a média ponderada e o desvio padrão para cada motivação, criando-se, assim, um ranking de importância das motivações (quanto mais próxima de 5 a média e quanto menor o desvio padrão da motivação, maior seu grau de importância). Para uma melhor compreensão dos resultados e para permanecer no TRP, as motivações iniciais foram categorizadas em dois grupos: sociais e econômicas, como mostram os quadros 1 e 2. Após a categorização das motivações, estruturam-se matrizes de correlação entre as motivações e as características 
socioeconômicas dos empreendimentos e proprietários rurais pesquisadas. Dessa forma, os dados foram organizados e tabulados no software Excel e posteriormente interpretados.

\section{RESULTADOS E DISCUSSÃO}

Por meio dos dados obtidos na pesquisa, pode-se observar que o perfil dos empreendedores de turismo rural pedagógico apresenta grande heterogeneidade quanto às características socioeconômicas. Segundo os resultados da Tabela 1, embora exista um número maior de homens à frente dos empreendimentos, também existem mulheres, jovens e idosos liderando as atividades pedagógicas, bem como empreendedores com elevado grau de escolaridade e agricultores com o ensino fundamental incompleto. Da mesma forma, conforme demonstram os resultados da Tabela 2, as propriedades rurais também apresentam características diversas. Entre os estabelecimentos de TRP pesquisados, há propriedades de agricultura familiar, agricultura empresarial e empreendimentos apenas de turismo rural, assim como propriedades que possuem áreas físicas que variam de 1 a mais de 100 hectares, o que demonstra que o TRP vai além de uma iniciativa de diversificação para pequenos produtores, mas também se apresenta como uma oportunidade interessante a novos investidores do meio urbano e rural.

Para Aliste (2014), atualmente as estruturas sociais estão mais complexas e as relações entre seus distintos grupos se fazem mais dinâmicas. Segundo o autor, junto aos agricultores se consolidam grupos de população com atividades não diretamente associadas à agricultura, que imprimem um novo dinamismo para o futuro dos âmbitos culturais e sistemas de valores distintos aos que têm sido dominantes no meio rural, o que explica os diferentes perfis de empreendedores e empreendimentos de TRP.

Em relação às principais motivações para empreender no segmento do turismo rural pedagógico, segundo os resultados da Tabela 3, na qual são apresentados os rankings de importância das motivações dentro das categorias sociais e econômicas, o grupo das motivações sociais foi considerado o mais relevante pela maioria dos proprietários rurais. Já as motivações econômicas, apesar de serem consideradas 
importantes por mais da metade dos entrevistados, os resultados revelam uma menor relevância no ranking de importância. Da mesma forma, no que tange às motivações sociais e econômicas para permanecer no turismo rural pedagógico, verificou-se que, conforme demonstram os resultados da Tabela 4, as razões sociais obtiveram uma maior relevância que as motivações econômicas.

Neste sentido, os resultados anteriores aderem as premissas de Barbieri (2010, p.2) de que:

O desenvolvimento do agroturismo e outros tipos de empresas não agrícolas é promovido como um meio para reduzir os desafios que os agricultores sofrem, no sentido de que eles possam aumentar as receitas e o lucro da exploração agrícola. No entanto, as evidências mostram que o desenvolvimento deste tipo de exploração não agrícola, não são movidas apenas por considerações econômicas, mas também por um conjunto de objetivos intrínsecos e relacionados ao mercado, como perseguir um estilo de vida rural, a criação de emprego para os membros da família e socialização com os visitantes.

Estudos desenvolvidos na América do Norte (MCGEHEE, KIM, 2004) e Europa (OLLENBURG, BUCKLEY, 2007) demonstram que as principais razões intrínsecas para empreender nos diversos segmentos do agroturismo e do turismo rural estão vinculadas a uma série de aspirações pessoais dos empresários e dos familiares. Segundo estes autores, os fatores mais citados são a geração de emprego e/ou a ocupação para os membros da família, a manutenção do estilo de vida rural, o conhecimento de pessoas interessantes, a educação dos visitantes, além de aspectos relacionados às características empreendedoras, como novos desafios, satisfação pessoal e outros. Dessa forma, o destaque, em nossa pesquisa, de fatores, como a valorização da agricultura por meio desse tipo de turismo, ocorre pelo fato de que atividades não agrícolas, como o agroturismo e o turismo rural, são responsáveis pelo estabelecimento de um vínculo entre turistas e atores locais promovendo a troca de conhecimentos e o intercâmbio cultural, afirmando-se como um instrumento de valorização do meio rural. Neste sentido, Wanderley (2000, p.31) argumenta:

A sociedade brasileira parece ter hoje um olhar novo sobre o meio rural. Visto sempre como a fonte de problemas - desenraizamento, miséria, isolamento, currais eleitorais etc. - surgem, aqui e ali, 
indícios de que o meio rural é percebido igualmente como portador de "soluções". Esta percepção positiva crescente, real ou imaginária, encontra no meio rural alternativas para o problema do emprego (reivindicação pela terra, inclusive dos que dela haviam sido expulsos), para a melhoria da qualidade de vida, através de contatos mais diretos e intensos com a natureza, de forma intermitente (turismo rural) ou permanente (residência rural) e através do aprofundamento de relações sociais mais pessoais, tidas como predominantes entre os habitantes do campo.

Para Fucks e Souza (2010), "[...] o turismo contribui para a reestruturação e resgate dos papéis dos indivíduos, no âmbito da família e da sociedade, à medida que oportuniza novas ocupações, postos de trabalho e novas formas de inserção social". Quanto à importância da educação de crianças e jovens em relação às atividades do meio rural, Nasers (2009) argumenta que se os visitantes compreenderem melhor a forma de vida rural, será mais fácil ter o apoio às práticas agrícolas quando necessário. Dessa forma, observa-se que a educação de crianças e jovens quanto à produção de alimentos está diretamente ligada à valorização da agricultura e do modo de vida rural, e estas por sua vez estão vinculadas, muitas vezes, à interpretação que os proprietários rurais fazem a respeito da agricultura como estilo de vida e não apenas como uma atividade econômica, como demonstrou o entrevistado 3 ao relatar que:

Minha motivação é o meu ideal, mostrar que não importa a idade que a gente tem, a gente pode fazer alguma coisa pela sociedade. $E$ também pela importância que eu vejo em resgatar o meio de fazer agricultura... é o passado presente no futuro, essa é a nossa ideia. É o prazer de mostrar coisas que foram perdidas (ENTREVISTADO 3, CAMINHOS RURAIS, 03/07/2014).

No que tange às motivações econômicas, embora tenham sido consideradas muito relevantes por uma percentagem menor de entrevistados do que as motivações sociais tanto no que se refere às motivações iniciais e para permanecer no TRP, estas ainda exercem um papel importante na obtenção de uma renda complementar. Para Evans e Ilbery (1989), os agricultores são frequentemente confrontados com duas opções para garantir sua permanência frente a um mercado agrícola em recessão: intensificar a produção ou diversificar em busca de fontes de rendas alternativas. Muitos agricultores precisam complementar 
a renda familiar e o turismo rural "representa uma relação simbiótica entre a agricultura e o turismo, pois áreas agrícolas marginais não são, muitas vezes, economicamente viáveis, mas juntos (turismo e agricultura) podem produzir uma combinação rentável" (MURPHY, 1986, p. 669), por isso a importância da renda adicional como motivação para empreender no TRP.

Neste contexto, Lane (2014) salienta que o turismo rural teve sua origem no interesse de vários pequenos agricultores e empreendedores rurais em "sobreviver" face aos retrocessos decrescentes da agricultura e de outras pequenas empresas rurais. Assim, além de representar uma fonte de renda alternativa e de emprego e/ou ocupação para os membros da família, o TRP é também uma forma de aliar o tempo livre dos proprietários rurais e agricultores, assim como os recursos naturais já disponíveis nas propriedades, a uma prática econômica viável. Segundo Nickerson, Black e McCool (2001), os proprietários rurais, em especial os agricultores, já possuem a terra e as atividades agrícolas que atraem as pessoas, portanto, torna-se razoável que eles utilizem plenamente os recursos que possuem.

Segundo Amanor-Boadu (2013), embora a decisão de embarcar em um processo de "adição de valor" seja simples e direta, ou seja, aumentando o valor de seus produtos, a decisão de permanecer no agroturismo é muitas vezes mais complexa. Assim, a importância dada às motivações sociais para permanecer no TRP, como a satisfação pessoal, pode ser compreendida pelo fato de que a partir do momento em que as expectativas iniciais de diversificação voltadas aos fatores econômicos não são atendidas, os proprietários rurais passam a ver este tipo de negócio (agroturismo) como não lucrativo, salientando as vantagens sociais no lugar das vantagens financeiras, como argumenta Vogeler (1975). Ainda de acordo com o autor, a permanência nesse tipo de negócio, mesmo sem frutos econômicos, caracteriza a autoexploração dos agricultores, ou seja, o desejo dos pequenos agricultores de se manterem na posição de capitalista.

Procurando elucidar a complexidade existente nas motivações das ações de empreendedorismo no meio rural, foram selecionados alguns dados dos estabelecimentos visitados e estes foram correlacionados com os diferentes fatores motivacionais para iniciar e permanecer no TRP. Neste sentido, observou-se 
que, quanto às motivações iniciais, a característica que mais influenciou de forma significativa na motivação dos empreendedores foi o tipo de atividade econômica desenvolvida em cada propriedade. Já quanto às razões para permanecer no TRP, o gênero apresentou-se como a característica de maior influência.

Dessa forma, os resultados da tabela 5 no que se refere às características relacionadas às atividades econômicas desenvolvidas nas propriedades: Grupo1 (AF+TR), Grupo 2 (TR) e Grupo 3 (AE+TR), os Grupos 1 e 3, diretamente envolvidos com a produção agropecuária, apontaram as motivações iniciais "Educar crianças e jovens quanto 'SA importância da produção de alimentos" e "Valorização da agricultura através desse tipo de turismo" como as mais relevantes, demonstrando como tais razões estão intimamente ligadas à importância das atividades agrícolas e agropecuárias desenvolvidas nessas propriedades rurais. Já o Grupo 2 (TR) relatou a "Renda Adicional" e a "Oportunidade de emprego para os membros da família" como as motivações de maior importância, evidenciando o papel do TRP como fonte de renda para o grupo de empreendedores que tem como principal atividade o turismo rural. Neste mesmo sentido, Nickerson, Black e McCool (2001) também verificaram opiniões divergentes entre os diferentes tipos de estabelecimentos (agrícolas, pecuaristas, agropecuários e destinados apenas ao turismo). As propriedades destinadas principalmente ao turismo de férias e que não se classificaram como fazendas ou ranchos apresentaram menor preocupação com a flutuação da renda agrícola e maior interesse em atender as demandas do mercado, demonstrando a relação entre os fatores motivacionais e as atividades econômicas da propriedade rural.

Já segundo os resultados apresentados na Tabela 6 referentes aos diferentes gêneros, as mulheres consideraram "O aumento da divulgação e da venda dos produtos locais após o início do TRP" como a motivação mais relevante; enquanto os empreendedores masculinos ressaltaram a "Satisfação pessoal" como a principal motivação. A maior preocupação das mulheres com a venda dos produtos locais está relacionada à responsabilidade que elas exercem sobre a produção dos produtos comercializados nas propriedades, como geleias, compotas, panificação e artesanatos, na medida em que os homens são responsáveis pelas atividades agrícolas e manutenção da propriedade. Assim, as mulheres são cada vez mais motivadas pela valorização do seu trabalho 
por meio da venda dos produtos locais. Neste sentido, Dieguez-Castrillon et al. (2012) afirmam que este tipo de negócio beneficia a equidade social por proporcionar uma via de entrada no mercado de trabalho rural. Segundo os autores, as mulheres, muito mais do que os homens, respondem aos habituais motivos de diversificação produtiva no rural: a geração de rendas que garanta a sobrevivência financeira.

Neste contexto, pode-se observar que, assim como as motivações sociais mostraram-se fundamentais para empreender no turismo rural pedagógico, a permanência dos empreendedores neste segmento também se mostra alicerçada nos fatores pessoais. No entanto, não se pode deixar de ressaltar a importância das motivações econômicas para alguns grupos de empreendedores, como é o caso dos proprietários rurais com menos experiência no âmbito do turismo rural, ou as mulheres que permanecem no TRP pelo aumento da divulgação e das vendas dos produtos locais. Assim, nossos resultados, além de possuírem suporte nas pesquisas desenvolvidas anteriormente realizadas na América do Norte e Europa, demonstram a complexidade do papel da motivação na ação empreendedora, como salienta Langevang et al. (2012), sendo necessário se compreender como esses fatores, independentemente e em conjunto, influenciam as motivações, mas também a dinâmica dos ambientes nos quais essas ações são postas em prática.

Em relação ao reconhecimento dos benefícios socioeconômicos pelos empreendedores de TRP, os resultados da pesquisa revelam que a maior parte dos entrevistados reconhece como principais benefícios do TRP os fatores substantivo-formal, seguido pelos benefícios sociais e formal-substantivo. Já os benefícios econômicos foram relatados como principais por apenas uma pequena parcela dos proprietários rurais.

O reconhecimento por parte dos empreendedores em relação aos benefícios sociais em parceria com os benefícios econômicos e vice-versa, bem como a importância dada aos ganhos sociais, é evidenciada por Schneider e Fialho (2000, p. 20) ao enfatizarem que:

O turismo rural propicia a valorização do ambiente onde está sendo explorado por sua capacidade de destacar a cultura 
e a diversidade natural de uma região, proporcionando a conservação e manutenção do patrimônio histórico, cultural e natural. Pode contribuir, neste sentido, para reorganização social e econômica local uma vez que proporciona benefícios diretos à população local que participa direta ou indiretamente das atividades relacionadas com o turismo.

Ou seja, além de promover a dinâmica econômica local por meio de fontes de renda não agrícolas, gerando empregos diretos e indiretos, fomentando o comércio local, atividades como o turismo rural, agroturismo e, neste caso, o TRP, promove também o resgate dos costumes, do modo de produção, do patrimônio cultural, desencadeando um processo de valorização do meio e dos atores locais envolvidos na prática do turismo. Desse modo, muitas vezes os aspectos sociais, como a valorização da agricultura e o intercâmbio cultural, passam a ser reconhecidos em primeiro plano pelos proprietários rurais, evidenciando sua satisfação sobre a reestruturação social que ocorre no meio rural a partir da interação "rururbana" promovida pelo turismo rural. De acordo com Calvente (2004), os benefícios econômicos diretos, como a geração de renda complementar e a criação de ocupações, podem parecer de pequena importância quando de uma análise estritamente econômica. Entretanto, frente aos problemas enfrentados pelas regiões agrícolas, estes aspectos demonstram a importância e a necessidade da busca alternativas viáveis.

Já no que tange às impressões da comunidade rural sobre o turismo rural pedagógico, todos os membros da comunidade rural conhecem uma ou mais propriedades rurais pedagógicas, e a maior parte dos entrevistados reconhecem as mudanças na comunidade rural após o início das atividades de TRP. Entre as principais mudanças descritas pelos entrevistados estão: o maior número de visitantes na área rural e o impacto no modo de pensar o meio, conforme o depoimento do membro da comunidade apresentado na sequência:

[...] Em longo prazo eu não sei te dizer, mas que tem um impacto tem. Na verdade, quando uma propriedade muda, começa a receber esse tipo de turismo, as demais propriedades passam a se questionar se ela não pode vir a ser também uma propriedade de TRP. Senão tem um impacto físico, tem pelo menos um impacto no modo de pensar o meio (ENTREVISTADO, COMUNIDADE CAMINHOS RURAIS, 19/07/2014). 
Corroborando com as afirmações dos entrevistados, Schneider (2006) afirma que atividades não agrícolas no meio rural, como o turismo, trata-se de um processo de mudança, com repercussões nas esferas social, econômica e cultural, que de um modo ou outro afetam a vida das pessoas e transformam a sua condição. Dessa forma, quando questionados a respeito do TRP promover ou não benefícios à comunidade rural, todos os entrevistados relataram acreditar no potencial desta atividade na promoção de benefícios. Para a maioria dos entrevistados, os benefícios visualizados estão ligados a fatores econômicos, principalmente a maior circulação de pessoas, aumentando dessa forma a divulgação e a venda de outros produtos presentes no meio rural. Já para os outros entrevistados, os principais benefícios gerados à comunidade são os ganhos econômicos em primeiro lugar aliados aos benefícios sociais, os benefícios sociais como principais ganhos aliados aos benefícios econômicos em segundo plano e os aspectos sociais.

A relevante impressão dos membros da comunidade entrevistados em relação aos ganhos econômicos e sociais que o TRP promove no âmbito local é explicada por Schneider (2006) ao afirmar que, no contexto das comunidades rurais, as relações de trocas decorrem e são realizadas a partir de um conjunto de relações interpessoais. Ou seja, dentro da esfera dessas comunidades é preciso perceber que outros valores e regras são considerados quando se quer determinar e conhecer os mecanismos que viabilizam as relações econômicas e comerciais. Dessa forma, atividades como o TRP são ferramentas capazes de promover determinados valores, como a confiança entre visitantes, pais e agricultores, essenciais na consolidação das relações econômicas no meio rural, como demonstram os relatos dos membros da comunidade em relação aos benefícios gerados pelo TRP. Para Brenes et al. (2011), essas iniciativas não são apenas um meio de beneficiar as famílias de agricultores envolvidas, mas também são um meio de contribuir para o desenvolvimento econômico local e regional. Ainda neste sentido, para Barbieri (2010), além de proporcionar benefícios aos empreendedores, o agroturismo preserva os serviços intangíveis que a terra fornece à sociedade, juntamente com a produção de alimentos, tais como amenidades ambientais, oportunidades de lazer, gestão da paisagem, da biodiversidade e da cultura. 
Sobre a valorização do meio rural por meio do TRP, a maioria dos membros das comunidades rurais entrevistados reconhece este efeito da atividade pedagógica no meio rural. De acordo com a maior parcela dos entrevistados que reconheceu a valorização do rural, esta é possível, pois permite que as novas gerações urbanas conheçam o meio rural e assim passem a valorizar e respeitar o meio ambiente e o trabalho do agricultor. Já outro grupo de entrevistados destacou que a valorização ocorre por meio do reconhecimento dos produtos locais e da produção de alimentos; enquanto para os demais entrevistados a valorização se dá a partir da oportunidade de novos postos de trabalho, o que permite que as novas gerações não precisem deixar o meio rural em busca de oportunidades. As diferentes impressões dos entrevistados em relação ao processo de "valorização do meio rural" por meio do TRP vão ao encontro do pensamento de Queiroz (2005,p.9) ao argumentar que:

A característica transdisciplinar e multissetorial do turismo permite a valorização dos aspectos naturais, da cultura e da atividade produtiva das comunidades familiares, e estimula, também, a recuperação e conservação da economia do território.

Dessa forma, observa-se que existe uma consciência sobre os efeitos, em sua maior parte positivos, que esta prática promove não apenas aos empreendedores e às suas famílias, mas também para a comunidade rural ao seu entorno. Embora muitas vezes parte da comunidade não consiga perceber as mudanças ocorridas, como mostram as informações apresentadas anteriormente, não deixam de relatar os benefícios e a importância do TRP na valorização do rural e na troca de experiências entre as diferentes gerações e meios. Neste sentido, para Yang (2012) o agroturismo tem sido apontado como um elemento significativo no desenvolvimento socioeconômico e no renascimento das regiões rurais. Entre as principais razões está sua contribuição econômica e social para as comunidades rurais, além disso, há outras razões, como o fornecimento de receitas adicionais para a exploração agrícola, a promoção e a proteção dos valores ambientais e culturais, bem como proporcionar uma fonte de emprego para as comunidades locais. 


\section{CONSIDERAÇÕES FINAIS}

A potencialidade do turismo rural pedagógico como ferramenta de troca de experiências, valores e vivências entre diferentes meios (urbano e rural) e gerações, bem como seu potencial como instrumento de apoio ao processo aprendizado e à oportunidade de negócio ficou evidenciada ao observar-se a heterogeneidade das características socioeconômicas dos empreendedores e dos empreendimentos que estão investindo nesta prática. Por representar uma atividade dinâmica que vai ao encontro das necessidades de uma sociedade pósmoderna, que busca o resgate de determinados valores como o contato com o modo de vida de seus antepassados, a reaproximação com a natureza, a troca de conhecimentos, entre outros, o TRP apresenta-se como uma prática capaz de atrair diferentes tipos de empreendedores e um crescente público escolar.

Quanto às motivações para empreender no TRP, observou-se que as razões sociais prevaleceram sobre os aspectos econômicos. Embora as diferentes atividades econômicas já desenvolvidas nas propriedades rurais tenham influenciado na motivação inicial, de modo geral, o que motivou os empreendedores a iniciaram esta atividade foi a valorização da agricultura e a educação dos consumidores aliadas à fonte de renda adicional. Da mesma forma, os aspectos sociais também se sobressaíram aos econômicos no que condizem às motivações para permanecer no turismo rural pedagógico. $O$ destaque dado por muitos proprietários rurais sobre a importância de manter sua qualidade de vida permanecendo no campo, assim como a importância do repasse de seus "saberes-fazeres" às novas gerações, ficou evidenciado na medida em que a maioria dos empreendedores relatou a satisfação pessoal, a interação e a troca de experiência com os visitantes e a valorização do rural como principais razões para manter-se no turismo rural pedagógico. No entanto, vale destacar que, para as mulheres, o principal motivo para permanecer no TRP está ligado ao aumento da divulgação e da comercialização dos produtos locais, o que ressalta a importância do turismo rural pedagógico na reorganização da estrutura familiar, promovendo maior espaço e participação às mulheres, que em sua maioria são as responsáveis pela produção dos produtos locais. 
Ainda no que se refere aos aspectos sociais do turismo rural pedagógico, para a maior parte dos empreendedores do projeto Viva Ciranda e roteiro Caminhos Rurais os ganhos sociais, aliados aos fatores econômicos, são os principais benefícios proporcionados pelo TRP. A relevância dada a fatores como a interação entre diferentes gerações, satisfação pessoal, troca de conhecimentos, associados ao aumento da venda de produtos locais e à renda adicional, salienta o reconhecimento por parte dos empreendedores, em especial dos agricultores, do TRP como uma prática capaz de valorizar sua cultura e preservá-la, além de proporcionar a geração de renda adicional.

Essa visão a respeito dos efeitos multiplicadores do TRP também ficou clara no reconhecimento dos membros da comunidade sobre os benefícios gerados por essa atividade. As propriedades de turismo rural pedagógico representam um elo entre os meios urbano e rural, o que permite a aproximação de diferentes gerações, a conexão entre produtores e consumidores e, desse modo, a afirmação do TRP como uma estratégia de reprodução socioeconômica. Assim, é justificável o reconhecimento da maior parte dos membros da comunidade rural em relação à importância dessa prática para a promoção de mudanças na comunidade por meio do aumento da circulação de visitantes no meio rural e o impacto no modo de pensar o meio.

Portanto, pode-se afirmar que o TRP apresenta-se como uma estratégia de desenvolvimento local, na medida em que utiliza os recursos endógenos da comunidade para proporcionar o dinamismo e o desenvolvimento social e econômico.

\section{REFERÊNCIAS}

ADAMS, B. The new agritourism: Hosting community and tourist on your farm. Auburn: CA New World, 2008.

ALISTE, J. B. La sociedad rural: Un viaje de ida y vuelta. In: CRISTÓVÃO et al. (Org.) Turismo rural em tempos de novas ruralidades. Porto Alegre: Ed. da UFRGS, 2014, p.217-238.

AMANOR-BOADU, V. Diversification Decisions in Agriculture: The Case of Agritourism in Kansas. International Food and Agribusiness Management Review, v. 16, n. 2, p. 57-74, 
2013. Disponível em http://ageconsearch.umn.edu/bitstream/148583/2/20110141.pdf>. Acesso em: 29 de setembro de 2014.

BARBIERI, C. An importance-performance analysis of the motivations behind agritourism and other farm enterprise developments in Canada. Journal of Rural and Community Development, Brandon, v.5, n. 1/2, p. 1-20, December, 2010. Disponível em: <http://www4. ncsu.edu/ cebarbie/papers/barbieri_IPA_2010.pdf >. Acesso em: 15 de setembro de 2014.

BRENES, E. R. et al. Corporate governance and family business performance. Journal of Business Research, Atenas, v.64, n.3, p. 280-285, March. 2011. Disponível em: < http:// www.sciencedirect.com/science/article/pii/S0148296309003014>. Acesso em: 23 de agosto de 2014.

CALVENTE, M. C. M. H. Turismo e excursionismo rural: potencialidades, regulação e impactos. Londrina: Humanidades, 2004

CAMPANHOLA, C.; GRAZIANO DA SILVA, J. O agroturismo como nova fonte de renda para o pequeno agricultor brasileiro. In: ALMEIDA, J. A.; RIEDL, M. (Org.). Turismo rural: ecologia, lazer e desenvolvimento. Bauru: EDUSC, 2000. p. 145-179.

CANDIOTTO, L. Z. P. Aspectos históricos e conceituais da multifuncionalidade da agricultura. In: ENCONTRO NACIONAL DE GEOGRAFIA AGRÁRIA, 2009, São Paulo. Anais...São Paulo: ENGA, 2009. Disponível em: <http://www.geografia.fflch.usp.br/inferior/laboratorios/ agraria/Anais\%20XIXENGA/artigos/Candiotto_LZP.pdf>. Acesso em: 15 de dezembro de 2013.

CARNEIRO, M. J. Pluriatividade da agricultura no Brasil: uma reflexão crítica. In: SCHNEIDER, S. (Org.). A diversidade da agricultura Familiar. Porto Alegre: Editora da UFRGS, 2006, p.165-185.

CAZELLA, A., BONNAL, P., MALUF, R.S. (Org.). Agricultura familiar: multifuncionalidade e desenvolvimento territorial no Brasil. Rio de Janeiro: Mauad, 2009.

DIEGUEZ-CASTRILLON, M. I. et. al, Turismo Rural, Empreendedorismo e Gênero: um estudo de caso na comunidade autônoma da Galiza. Revista de Economia e Sociologia Rural, Piracicaba, v. 50, n. 2, p. 371-382, abr/jun 2012. Disponível em: <http://www.scielo.br/scielo.php?script=sci_ arttext\&pid=S0103-20032012000200010 > . Acesso em: 15 de setembro de 2014 .

EVANS, N. J., ILBERY, B. W. A Conceptual Framework for Investigating Farm-Based Accommodation and Tourism in Britain. Journal of Rural Studies, New York, v.5, n.3, p. 257-266, August.1989. Disponível em: http://www.sciencedirect.com/science/article/ pii/074301678990004. Acesso em: 3 de maio de 2014.

Revista Turismo - Visão e Aç̃̃o - Eletrônica, Vol. 17 - N. 3 - Set. - Dez. 2015 
FUCKS, P. M.; SOUZA, M. Turismo no espaço rural e preservação do patrimônio, da paisagem e da cultura. In: SANTOS, E. O.; SOUZA, M. Teoria e prática do turismo no espaço rural. Barueri: Manole, 2010, p. 96-108.

GRAZIANO, S. J. O Novo Rural Brasileiro. In: SHIKI, S., GRAZIANO DA SILVA, J., ORTEGA, A. C. (Org.). Agricultura, meio ambiente e sustentabilidade do cerrado brasileiro. Uberlândia: UFU; UNICAMP; EMBRAPA, 1997, p.75-99.

GRAZIANO DA SILVA, J. F; CAMPANHOLA, C. Diretrizes de políticas públicas para o novo rural brasileiro: incorporando a noção de desenvolvimento local. In: CAMPANHOLA, C.; GRAZIANO DA SILVA, J. F. (Org.). O novo rural brasileiro: políticas públicas. Jaguariúna/SP, 2000, v. 4, p. 61-91.

HINRICHS, C. et al. Growing the links between farms and schools: a how-to guidebook for Pennsylvania farmers, schools and communities. Harrisburg, PA: The Center for Rural Pennsylvania, November. 2008. Disponível em: <http://www.rural.palegislature.us/Farm_ School_Guide08.pdf>. Acesso em: 15 de junho de 2013.

KAGEYAMA, A. Desenvolvimento Rural: conceitos e aplicação ao caso brasileiro. Porto Alegre: Ed. da UFRGS, 2008.

KLEIN, A. L. A função educativa das propriedades rurais e o turismo rural pedagógico: duas experiências na região Sul do Brasil. 2012. 170 f. Dissertação (Mestrado em Desenvolvimento Rural) - Universidade Federal do Rio Grande do Sul, Faculdade de Ciências Econômicas, Porto Alegre, 2012.

KLEIN, A.; TROIAN, A.; SOUZA, M. O turismo rural pedagógico e a educação ambiental: as ações pedagógicas desenvolvidas na fazenda quinta da estância grande Viamão (RS). Revista Eletrônica do Mestrado em Educação Ambiental, Rio Grande, v. 27, p. 107-121, 2011. Disponível em: < http://www.seer.furg.br/remea/article/view/3197>. Acesso em: 13 de julho de 2013.

LANE. B. Turismo rural de segunda geração: Prioridades e questão de pesquisa. In: CRISTÓVÃO, A.; PEREIRO, X. (Org.). Turismo rural em tempos de novas ruralidades. Ed. da UFRGS, Porto Alegre, 2014, p.15-48.

LANGEVANG, T., NAMATOVU, R., DAWA, S. Beyond Necessity and Opportunity Entrepreneurship: Motivations and Aspirations of Young Entrepreneurs in Uganda. International Development Planning Review, Liverpool, v. 34, n.4, p.339-459, September. 2012. Disponível em: <http://liverpool.metapress.com/content/32p651v86t73460u/> . Acesso em: 16 de Agosto de 2014. 
MCENROE, K.B. Public education of integrated farm systems using agri-tourism. These (Master of Landscape Architecture) - Pomona, Faculty of California State Polytechnic University, 2010.

MCGEHEE, N.; KIM, K. Motivation for agritourism entrepreneurship. Journal of Travel Research, Thousand Oaks, v. 43, n. 2, p. 161-170, November.2004.Disponível em: <http:// jtr.sagepub.com/content/43/2/161.short >. Acesso em: 20 de maio de 2014.

MURPHY, P. E. Tourism: A Community Approach. Annals of Tourism Research. New York, v.13, n. 4, p. 667-669, April. 1986. Disponível em: <http://www.sciencedirect.com/science/ article/pii/0160738386900125 >. Acesso em: 15 de outubro de 2014.

NASERS, M. S. Iowa agritourism consumer profile: demographics, preferences, and participation levels. These (Master of Science) - Iowa State University, Faculty of Agricultural Education, Ames, 2009. Disponível em: <http://lib.dr.iastate.edu/cgi/viewcontent. cgi? article $=1728 \&$ context $=$ etd $>$. Acesso em: 13 de março de 2013.

NICKERSON, N. P., BLACK, R.J. and MCCOOL, S. F. Agritourism: Motivations behind Farm/ Ranch Business Diversification. Journal of Travel Research, Thousand Oaks, v.40, n. 1, p.19-26, August. 2001. Disponível em: < http://jtr.sagepub.com/content/40/1/19.abstract> . Acesso em: 17 de maio de 2014.

$\mathrm{OHE}, \mathrm{Y}$. Multifunctionality and rural tourism: a perspective on farm diversification, Journal of International Farm Management, Cambridge, v. 4, p. 1-23, jun. 2007.Disponível em: <http://www.ifmaonline.org/pdf/journals/Vol4Ed1_Ohe.pdf >. Acesso em: 03 de abril de 2013.

OLLENBURG, C., BUCKLEY, R. State Economic and Social Motivations of Farm Tourism Operators. Journal of Travel Research, Thousand Oaks, v. 45, p.444-452, May. 2007. Disponível em: < http://jtr.sagepub.com/content/45/4/444.full.pdf>. Acesso em: 16 de setembro de 2014.

QUEIROZ, P. G. Turismo Rural e Desenvolvimento Local na Agricultura Familiar. In: Congressos da sociedade brasileira de economia, administração e sociologia rural, n.43, 2005, Ribeirão Preto. Anais... Ribeirão Preto, SP: SOBER, 2005. p. 1-14. Disponível em: <http://www.sober. org.br/palestra/2/373.pdf >. Acesso em: 15 de outubro de 2014.

SCHNEIDER, S. (Org.). A diversidade da agricultura familiar. Porto Alegre: Editora da UFRGS, 2006. 
SCHNEIDER, S.; FIALHO, M. A. V. Atividades não agrícolas e turismo rural no Rio Grande do Sul. In: ALMEIDA, J. A.; RIEDEL, M. (Org.) Turismo rural: ecologia, lazer e desenvolvimento. Bauru: Edusc, 2000, p. 15-50.

TULIK, O. Turismo rural. São Paulo: Aleph, 2003. (ABC do Turismo).

WANDERLEY, M. N. B. A emergência de uma nova ruralidade nas sociedades modernas avançadas - o "rural" como espaço singular e ator coletivo. Rio de Janeiro: editora da UFRRJ, 2000.

YANG. L. Impacts and challenges in agritourism development in Yunnan, China. Tourism Planning \&Development, Brigthon, v.9, n.4, p.369-381, October. 2012. Disponível em: <http://www.tandfonline.com/doi/abs/10.1080/21568316.2012.726257\#.VMvNPNLF_io>. Acesso em: 13 de maio de 2014.

ANEXOS

Quadro 1 - Categorização das motivações iniciais e para permanecer no turismo rural pedagógico

\begin{tabular}{|c|c|}
\hline Motivações Sociais & Motivações Econômicas \\
\hline $\begin{array}{c}\text { Valorização da agricultura por meio } \\
\text { desse tipo de turismo } \\
\text { Educar crianças e jovens quanto } \\
\text { a importância da produção de } \\
\text { alimentos } \\
\text { Hobby }\end{array}$ & $\begin{array}{c}\text { Renda adicional } \\
\text { O sucesso de outras propriedades de turismo rural pedagógico } \\
\text { Utilizar o tempo livre e os recursos naturais disponíveis na } \\
\text { propriedade } \\
\text { Oportunidade de emprego para os membros da família } \\
\text { Aumento da procura e venda dos produtos locais } \\
\text { Variação do preço dos produtos agrícolas }\end{array}$ \\
\hline Motivações Sociais & Motivações Econômicas \\
\hline $\begin{array}{l}\text { Satisfação pessoal } \\
\text { Interação e troca de experiências } \\
\text { com os visitantes } \\
\text { Valorização do rural pelos visitantes }\end{array}$ & $\begin{array}{c}\text { Aumento da divulgação e a venda dos produtos locais após o } \\
\text { início do TRP } \\
\text { Importância da renda obtida por meio do TRP } \\
\text { Ocupação/emprego para os membros da família }\end{array}$ \\
\hline
\end{tabular}

Fonte: Elaborado pela autora com base em Nickerson, Black e McColl (2001). 
Tabela 1 - Perfil socioeconômico dos empreendedores de turismo rural pedagógico pertencentes ao roteiro Caminhos Rurais e projeto Viva Ciranda

\begin{tabular}{lcc}
\hline \multicolumn{1}{c}{ Caracteristicas } & Número & $\%$ \\
\hline Gênero & 4 & 28,57 \\
Feminino & 10 & 71,43 \\
Masculino & & \\
Faixa Etária & 3 & 21,4 \\
Até 30 anos & 8 & 57,1 \\
$31-60$ anos & 3 & 21,4 \\
$>60$ anos & & \\
Escolaridade & 4 & 28,57 \\
Ensino Fundamental & 3 & 21,43 \\
Ensino Médio & 7 & 50,00 \\
Ensino Superior & & \\
Profissão & 7 & 50,00 \\
Agricultor & 5 & 36,00 \\
Empresário & 2 & 14,00 \\
Turismólogo & & \\
\hline
\end{tabular}

Fonte: Elaborada pela autora com base nos dados da pesquisa de campo (2015).

Tabela 2 - Perfil socioeconômico dos empreendimentos de turismo rural pedagógico participantes do projeto Viva Ciranda e roteiro Caminhos Rurais

\begin{tabular}{ccc}
\hline Características & Número & $\mathbf{\%}$ \\
\hline Área da propriedade & & \\
\hline Até 10 ha & 7 & 50,00 \\
10,1-100 ha & 4 & 28,57 \\
$>100$ ha & 3 & 21,43 \\
\hline Tipo de empreendimento & & \\
\hline Grupo 1 (AF+TR) & 7 & 50,00 \\
Grupo 2 (TR) & 4 & 28,57 \\
Grupo 3 (AE+TR) & 3 & 21,43 \\
\hline Tempo de trabalho no TR & & \\
\hline Até 3 anos & 2 & 14,29 \\
3-10 anos & 5 & 35,71 \\
>10 anos & 7 & \\
\hline Localidade & & 28,00 \\
\hline Porto Alegre & 4 & 71,43 \\
Joinville & 10 & $\mathbf{1 0 0}$ \\
\hline TOTAL & $\mathbf{1 4}$ & \\
\hline
\end{tabular}

Fonte: Elaborada pela autora com base nos dados da pesquisa de campo (2015). 
Tabela 3 - Motivações econômicas e sociais iniciais dos empreendedores de TRP do projeto Viva Ciranda e roteiro Caminhos Rurais

\begin{tabular}{|c|c|c|c|c|}
\hline Motivações Econômicas & Média & Desvio Padrão & Relevantes $^{1}(\%)$ & Não Relevantes ${ }^{2}(\%)$ \\
\hline Renda adicional & 4,50 & 0,65 & 92,8 & 7,2 \\
\hline $\begin{array}{l}\text { O sucesso de outras } \\
\text { propriedades de turismo rural } \\
\text { pedagógico }\end{array}$ & 4,29 & 0,61 & 85,7 & 14,3 \\
\hline $\begin{array}{l}\text { Oportunidade de emprego para } \\
\text { os membros da família }\end{array}$ & 3,71 & 1,33 & 64,3 & 35,7 \\
\hline $\begin{array}{l}\text { Aumento da procura e venda } \\
\text { dos produtos locais }\end{array}$ & 3,64 & 1,22 & 57,1 & 42,9 \\
\hline $\begin{array}{l}\text { Variação dos preços dos } \\
\text { produtos agrícolas }\end{array}$ & 2,57 & 1,55 & 28,6 & 71,4 \\
\hline Motivações Sociais & Média & Desvio Padrão & Relevantes (\%) & Não Relevantes (\%) \\
\hline $\begin{array}{l}\text { Valorização da agricultura } \\
\text { através desse tipo de turismo }\end{array}$ & 4,79 & 0,58 & 92,8 & 7,2 \\
\hline $\begin{array}{l}\text { Educar crianças e jovens } \\
\text { quanto a importância da } \\
\text { produção de alimentos }\end{array}$ & 4,79 & 0,80 & 92,8 & 7,2 \\
\hline $\begin{array}{l}\text { Utilizar o tempo livre e os } \\
\text { recursos naturais disponiveis na } \\
\text { propriedade }\end{array}$ & 4,07 & 1,00 & 85,7 & 14,3 \\
\hline Hobby & 3,57 & 1,28 & 35,7 & 64,3 \\
\hline Motivações Sociais & 4,3 & 1,06 & $84 \%$ & $16 \%$ \\
\hline Motivações Econômicas & 3,7 & 1,29 & $67 \%$ & $33 \%$ \\
\hline
\end{tabular}

Fonte: Elaborada pela autora com base nos dados da pesquisa de campo (2015).

${ }^{1}$ Corresponde a \% de respostas relevante e muito relevante;

${ }^{2}$ Corresponde a \% de respostas não relevante, pouco relevante e neutro;

Tabela 4 - Ranking das motivações sociais e econômicas para os empreendedores permanecerem no Turismo Rural Pedagógico no projeto Viva Ciranda e roteiro Caminhos Rurais

\begin{tabular}{|c|c|c|c|c|}
\hline Motivações Sociais & Média & DP & $\%$ Relevante $^{1}$ & \% Não Relevante ${ }^{2}$ \\
\hline Satisfação pessoal & 4,93 & 0,27 & 100 & 0 \\
\hline $\begin{array}{l}\text { Valorização do rural pelos } \\
\text { visitantes }\end{array}$ & 4,79 & 0,43 & 100 & 0 \\
\hline $\begin{array}{l}\text { Interação e troca de } \\
\text { experiências com os } \\
\text { visitantes }\end{array}$ & 4,79 & 0,43 & 92,9 & 7,1 \\
\hline Motivações Econômicas & Média & DP & \% Relevante ${ }^{1}$ & \% Não Relevante ${ }^{2}$ \\
\hline $\begin{array}{l}\text { Aumento da divulgação e } \\
\text { venda dos produtos locais } \\
\text { após o início do TRP }\end{array}$ & 4,21 & 0,97 & 78,6 & 21,4 \\
\hline $\begin{array}{l}\text { Importância da renda obtida } \\
\text { através do TRP }\end{array}$ & $4,07^{1}$ & 1,07 & 64,3 & 35,7 \\
\hline $\begin{array}{l}\text { Ocupação/emprego para os } \\
\text { membros da familia }\end{array}$ & 3,71 & 0,99 & 71,4 & 28,6 \\
\hline
\end{tabular}

Fonte: Elaborada pela autora com base nos dados da pesquisa de campo (2015).

Nota: DP = Desvio Padrão 
Tabela 5 - Ranking das motivações para empreender no TRP, segundo os grupos tipificados nas propriedades rurais pertencentes ao projeto Viva Ciranda e roteiro Caminhos Rurais

\begin{tabular}{lcccccc}
\hline \multicolumn{1}{c}{ Motivações } & \multicolumn{2}{c}{ Grupo 1 (AF+TR) } & \multicolumn{2}{c}{$\begin{array}{c}\text { Grupo 2 } \\
\text { (TR) }\end{array}$} & \multicolumn{2}{c}{$\begin{array}{c}\text { Grupo 3 } \\
\text { (AE+TR) }\end{array}$} \\
\cline { 2 - 7 } & Média & DP & Média & DP & Média & DP \\
\hline $\begin{array}{l}\text { Educar crianças e jovens quanto a } \\
\text { importância da produção de alimentos }\end{array}$ & 5 & 0,00 & 4,25 & 1,50 & 5 & 0,00 \\
$\begin{array}{l}\text { Valorização da agricultura através desse } \\
\text { tipo de turismo }\end{array}$ & 4,86 & 0,38 & 4,5 & 1,00 & 5 & 0,00 \\
$\quad \begin{array}{l}\text { Renda adicional } \\
\text { Aumento da procura e venda dos }\end{array}$ & 4,57 & 0,53 & 4,75 & 0,50 & 4 & 1,00 \\
produtos locais através do TRP & 4,29 & 0,95 & 3 & 1,41 & 3 & 1,00 \\
$\begin{array}{l}\text { O sucesso de outras propriedades de } \\
\text { turismo rural pedagógico }\end{array}$ & 4,29 & 0,95 & 4,25 & 0,50 & 4 & 1,00 \\
$\begin{array}{l}\text { Utilizar o tempo livre e os recursos } \\
\text { naturais disponiveis na propriedade }\end{array}$ & 4,14 & 1,07 & 3,75 & 1,26 & 4,33 & 0,58 \\
$\begin{array}{l}\text { Oportunidade de emprego para os } \\
\text { membros da família }\end{array}$ & 3,86 & 1,07 & 4,75 & 0,50 & 3 & 1,00 \\
$\begin{array}{l}\text { Hobby } \\
\text { Variação dos preços dos produtos }\end{array}$ & 3,71 & 0,76 & 3,5 & 1,73 & 3,33 & 2,08 \\
agrícolas & 3 & 1,53 & 2,5 & 1,91 & 1,67 & 1,15 \\
\hline
\end{tabular}

Fonte: Elaborada pela autora com base nos dados da pesquisa de campo (2015).

Nota: DP = Desvio Padrão

Tabela 6-Motivações para permanecer no TRP, segundo o gênero dos empreendedores do projeto Viva Ciranda e roteiro Caminhos Rurais

\begin{tabular}{lcccc}
\hline \multicolumn{1}{c}{ Motivações } & \multicolumn{2}{c}{ Feminino } & \multicolumn{2}{c}{ Masculino } \\
\cline { 2 - 5 } & Média & DP & Média & DP \\
\hline $\begin{array}{l}\text { Aumento da divulgação e venda dos } \\
\text { produtos locais após o início do TRP }\end{array}$ & 5,00 & 0,00 & 4,00 & 1,00 \\
$\begin{array}{l}\text { Interação e troca de experiências com } \\
\text { OS visitantes }\end{array}$ & 4,67 & 0,58 & 4,82 & 0,40 \\
$\begin{array}{l}\text { Satisfação pessoal } \\
\text { Valorização do rural pelos visitantes }\end{array}$ & 4,67 & 0,58 & 5,00 & 0,00 \\
$\begin{array}{l}\text { Importância da renda obtida através do } \\
\text { TRP }\end{array}$ & 4,67 & 0,58 & 4,82 & 0,40 \\
$\begin{array}{l}\text { Ocupação/emprego para os membros } \\
\text { da família }\end{array}$ & 2,67 & 1,15 & 4,00 & 1,10 \\
& & & & \\
\end{tabular}

Fonte: Elaborada pela autora com base nos dados da pesquisa de campo (2015).

Nota: DP = Desvio Padrão 